\title{
Calculation of Seven Photovoltaic Cells Parameters Using Parallelized Successive Discretization Algorithm
}

\author{
Adrian M. Deaconu $\mathbb{D}^{1},{ }^{1}$ Daniel T. Cotfas $\mathbb{D}^{2}$, and Petru A. Cotfas $\mathbb{D}^{2}$ \\ ${ }^{1}$ Faculty of Mathematics and Computer Science, Transilvania University of Brasov, Brașov, Romania \\ ${ }^{2}$ Faculty of Electrical Engineering and Computer Science, Transilvania University of Brasov, Braşov, Romania \\ Correspondence should be addressed to Adrian M. Deaconu; a.deaconu@unitbv.ro
}

Received 8 October 2020; Revised 20 November 2020; Accepted 26 November 2020; Published 11 December 2020

Academic Editor: Elias Stathatos

Copyright (c) 2020 Adrian M. Deaconu et al. This is an open access article distributed under the Creative Commons Attribution License, which permits unrestricted use, distribution, and reproduction in any medium, provided the original work is properly cited.

\begin{abstract}
Some parameters must be calculated with very good accuracy for the purpose of designing, simulating, and evaluating the performance of a photovoltaic system. The seven parameters of the photovoltaic cell and panels for the two-diode model are determined using a parallelized metaheuristic algorithm based on successive discretization. The parameters obtained for a photovoltaic cell and four panels using the proposed algorithm are compared with the ones calculated through over twenty methods from recent research literature. The root mean square error is used to prove the superiority of the Parallelized Successive Discretization Algorithm (PSDA). The smallest values for root mean square error (RMSE) in both cases, photovoltaic cell and panels, are obtained for the algorithm presented in this paper. The seven parameters for three panels known in the specialised literature, Kyocera KC200GT, Leibold Solar Module LSM 20, and Leybold Solar Module STE 4/100 are determined for the first time using PSDA.
\end{abstract}

\section{Introduction}

Fossil fuel is inevitable exhausting, and its price has continually increased in the last decades. There is also an increasing concern on the environmental pollution and on the climate changes related to the use of fossil fuel. It is strongly believed that the renewable energy is the clean alternative solution of today and for the future. Many researchers have focused on renewable solar energy in general and, in particular, on the generation of electric power using photovoltaic cells which is desired to become in the near future one of the most important energy sources.

Nowadays, there are many photovoltaic cells types, some of them relatively new, such as Perovskite or multijunctions-triple or four junctions, which must be analyzed and characterized to optimize their efficiency. Very good photovoltaic panels are achieved if the photovoltaic cells used are "twins." This can be realized if the photovoltaic cells are characterized before the fabrication process of the photovoltaic panels, and they are selected so that the parameters have the same values.
The characterization process must be very fast so as to increase the productivity.

Some parameters must be calculated with very good precision for the purpose of designing, simulation, and evaluation of the performance of a photovoltaic system. Nowadays, the estimation of these parameters is an important research topic, for which researchers develop new methods and algorithms. The parameters of the photovoltaic cells and panels can be determined using the current voltage characteristic, called I-V characteristic in the following, equivalent circuit, and the mathematical model $[1,2]$. The one-diode model is generally used to determine the parameters of the photovoltaic cells, due to the simplicity and good agreement for the parameters results [3]. Lately, the researchers are using the two-diode model to determine the photovoltaic cells parameters, especially for the monocrystalline and polycrystalline silicon photovoltaic cells and panels. In this case, both mechanisms, the diffusion and the generation and recombination, are taken into account. Using the two-diode model leads to growth accuracy with which the parameters of the photovoltaic cells are determined. 
The parameters of the photovoltaic cells and panels were determined using graphical analysis and numerical analysis with different approximation [1]. The metaheuristic algorithms based on natural phenomena were used lately with success because are suitable for nonlinear multimodal as is the problem for photovoltaic devices. The parameters of the photovoltaic cells and panels using the metaheuristic algorithms are calculated with high accuracy due to avoiding the errors made through approximation in the other methods, and the necessary time for their determination is reduced continuously due to the optimization of the algorithms and use of the hybrid algorithms [3].

We shall briefly present below the best currently known algorithms for determining the solar cell parameters. They are taken into consideration to compare their performance against the Parallelized Successive Discretization Algorithm (PSDA) presented in this paper. Most of these algorithms are metaheuristic methods inspired from the behavior of populations of different groups of people or from the behavior of swarms of animals or insects. Population classification evolution algorithm (PCE) is an evolutional algorithm, with a fast convergence speed and a very good accuracy [4]. Simplified TBLO (STBLO) [5] and generalized oppositional TBLO (GOTBLO) [6] are improved versions of teaching-learningbased optimization (TLBO) algorithm which is a population-based method. Improved shuffled complex evolution (ISCE) is an improved version of complex evolution strategy (SCE) which was applied with success to calculate the parameters of one-diode and two-diode models for photovoltaic cell and for panel [7]. Rcr-IJADE has better performance than other classic or adaptive differential evolution algorithms [8]. MABC is a modified version of artificial bee colony (ABC) algorithm with better results than the regular ABC [9]. EHA-NMS and NM-MPSO are hybrid algorithms and are based on Nelder-Mead and MABC [10] and, respectively, particle swarm optimization PSO [9]. Cat swarm optimization algorithm (CSO) is developed by analyzing the behaviors of cats. The performance of CSO surpasses that of PSO [11]. Bird mating optimizer (BMO) tries to imitate the mating strategies of bird species, without premature convergence, and thus, its solution is close to the global one [12]. Chaotic whale optimization algorithm (CWOA) is an algorithm developed on the hunting mechanism of humpback whales, and it can refine complex and multimodal objective functions [13]. Artificial bee swarm optimization algorithm (ABSO) is based on the intelligent behaviors of honey bees such as collection and processing of nectar [12]. Innovative global harmony search (IGHS) and grouping-based global harmony search (GGHS) algorithms are improved versions of the harmony search algorithm trying to imitate the improvisation process of musicians [14]. Simulated annealing (SA) is a single-searcher algorithm with less chance to find the global minimum [15]. Guaranteed convergence particle swarm optimization (GCPSO) [16] is an improved version of the PSO algorithm, and it has the ability to avoid premature convergence and to determine the parameters of the photovoltaic panels quickly and accurately. Time-varying acceleration coefficients particle swarm optimization (TVACPSO) is an improved PSO. WDOWOAPSO is a hybrid method based on PSO and the wind-driven optimization (WDO) technique [17]. Artificial Bee ColonyDifferential Evolution (ABC-DE) resulted from ABC, and its performance is improved for finding the global optimum and for convergence speed [18]. Flexible particle swarm optimization (FPSO) improves the PSO algorithm through increasing the ability of global search [19].

In this paper, a metaheuristic algorithm based on the discretization process of functions that systematically try to improve the approximate solution is presented. Discretization is defined in Mathematics as the continuous functions, variables, models, and equations transferred into discrete counterparts. It usually represents the first stage of achieving proper values for numerical evaluation or implementation on digital computers. Such techniques are implemented in order to solve miscellaneous problems [20], among the optimizing ones [21]. If continuous data is discretized, discretization error appears in various amounts. The aim is decreasing the errors down to a negligible value in terms of modeling scope.

The idea of successive discretization algorithm (SDA) applied for parameter estimation of PV cells is to compute a set of approximate solutions selected from values obtained by a discretization process and having the minimum root mean square error. Around each of these selected values, a more refined discretization is performed and a new set of approximate solutions is selected and so on. The successive discretization process performed a preset number of iterations or until no better solution is found than the best solution found so far in the previous iteration.

In this paper, we adapt and implement SDA in parallel for the two-diode model, and we compare the obtained solution with the solutions given by the best known methods at the moment. The novelty and the contributions of the paper are

(i) the new algorithm PSDA is presented in the paper

(ii) the results obtained for the RMSE for all devices under analysis are the best in comparison with the other algorithms from the specialised literature

(iii) the time needed to extract the parameters of the photovoltaic cell and panels for the two-diode model increases, and the PSDA algorithm is the proper tool to reduce it; the duration is reduced 6 times using the PSDA in comparison with SDA algorithm

(iv) three datasets are analyzed for the first time using the two-diode model: Kyocera KC200GT, Leibold Solar Module LSM 20, and Leybold Solar Module STE 4/100.

\section{Method}

2.1. Models for Photovoltaic Cell and Panel. The equivalent circuit of the photovoltaic panel is presented in Figure 1, and the mathematical model is given by Eq. (1). The following seven parameters can be determined: the photogenerated current $I_{\mathrm{ph}}$, the reverse saturation current $I_{\mathrm{od}}$ and ideality factor of diode $n_{\mathrm{d}}$ which correspond to diffusion mechanism, 


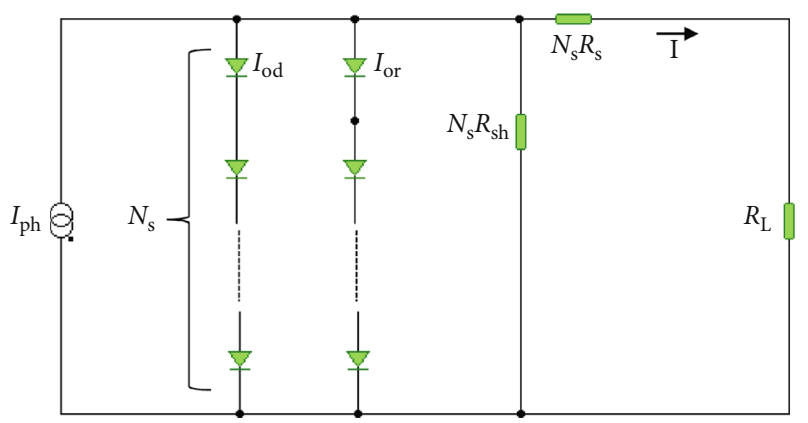

Figure 1: Equivalent circuits of photovoltaic panel. Two-diode model.

the reverse saturation current $I_{\text {or }}$ and ideality factor of diode $n_{\mathrm{r}}$ which correspond to generation and recombination mechanism, and the parasitic resistance-series resistance $R_{\mathrm{s}}$ and shunt resistance $R_{\mathrm{sh}}$ [1]. $N_{\mathrm{s}}$ is the number of the photovoltaic cells connected in series. $N_{\mathrm{s}}$ is one in case of the photovoltaic cell.

$$
I=I_{p h}-I_{o d}\left(e^{\frac{V+\mathrm{IN}_{s} R_{s}}{n_{d} N_{s} V}}-1\right)-I_{\mathrm{or}}\left(e^{\frac{V+\mathrm{IN}_{s} R_{s}}{n_{r} V_{s} V_{T}}}-1\right)-\frac{V+\mathrm{IN}_{s} R_{s}}{N_{s} R_{s h}}
$$

2.2. Parallelized Successive Discretization Algorithm. SDA algorithm was successfully applied for the one-diode model in [3]. It was compared with other methods used to determine the parameters of the photovoltaic cells and panels. SDA proved to be the best among the known methods at the moment the article was published. In this paper, we adapt SDA to solve the more complex problem of estimating the seven parameters for the two-diode model. Since the amount of calculations is considerably higher than for the one-diode model, a direct adaptation of SDA for the two-diode model leads to a very slow algorithm or to an algorithm that finds a low-quality solution. Therefore, a parallel implementation of SDA is needed, fast enough and able to compute very good solutions. In the production process of photovoltaic panels, it is very important to accurately and quickly estimate the cell parameters.

2.2.1. Discretization Process. The PSDA algorithm is based on discretization, which transfers continuous functions and equations into discrete counterparts. When the continuous data are discretized, some errors can appear, and the target is to reduce them [3].

We denote by

$$
\begin{aligned}
F_{I, V}^{2}\left(I_{\mathrm{ph}}, I_{\mathrm{od}}, n_{\mathrm{d}}, I_{\mathrm{or}}, n_{\mathrm{r}}, R_{\mathrm{s}}, R_{\mathrm{sh}}\right)= & I_{\mathrm{ph}}-I_{\mathrm{od}}\left(e^{\frac{V+\mathrm{IR}_{s}}{n_{d} V_{T}}}-1\right) \\
& -I_{\mathrm{or}}\left(e^{\frac{V+\mathrm{IR}_{s}}{n V_{T}}}-1\right) \\
& -\frac{V+\mathrm{IR}_{s}}{R_{\mathrm{sh}}}-I .
\end{aligned}
$$

Using Equations (1) and (2), the following equation is obtained:

$$
F_{I, V}^{2}\left(I_{\mathrm{ph}}, I_{o d}, n_{d}, I_{\mathrm{or}}, n_{r}, R_{s}, R_{\mathrm{sh}}\right)=0
$$

The root mean square error (RMSE), given by Equation (4), has to be minimized for the photovoltaic cell and panel parameters, $I_{\mathrm{pH}}, I_{o d}, n_{d}, I_{\mathrm{or}}, n_{r}, R_{s}$, and $R_{s h}$ calculated for the given pairs of current and voltage $(I, V)$.

$$
\operatorname{RMSE}\left(I_{\mathrm{ph}}, I_{o d}, n_{d}, I_{\mathrm{or}}, n_{r}, R_{s}, R_{\mathrm{sh}}\right)=\sqrt{\frac{\sum\left(F_{I, V}^{2}\left(I_{\mathrm{ph}}, I_{o d}, n_{d}, I_{\mathrm{or}}, n_{r}, R_{s}, R_{\mathrm{sh}}\right)\right)^{2}}{p}},
$$

where $p$ represents the number of the given $(I, V)$ pairs.

The intervals $J_{i}=\left[a_{i}, b_{i}\right](i=1,2, \cdots, 7)$ are considered for the definition of domains for the seven parameters enumerated before.

The function $F_{I, V}^{2}$ is continuous on the 7-dimensional interval $J_{1} \times J_{2} \times J_{3} \times J_{4} \times J_{5} \times J_{6} \times J_{7}$, which is called the discretization $7 \mathrm{D}$ interval. The discretization process is applied to the objective function $F_{I, V}^{2}$. The solution is searched in $J_{1} \times J_{2} \times J_{3} \times J_{4} \times J_{5} \times J_{6} \times J_{7}$. This $7 \mathrm{D}$ interval is the given boundaries for the searched solutions.

For each interval $J_{i}$, a positive integer $d_{i} \in N^{*}$ is considered $(i=1,2, \cdots, 7)$. Inside each of these 7 intervals, the values $v_{j}^{i}\left(j=1, \cdots, d_{i}\right)$ are taken so that

$$
a_{i}<v_{1}^{i}<v_{2}^{i}<\cdots<v_{d_{i}}^{i}<b_{i}
$$

The values $v_{j}^{i}\left(j=1, \cdots, d_{i}\right)$ are calculated using Equation (6) in order to obtain a good uniform distribution of the points in the interval $J_{i}$ :

$$
v_{j}^{i}=a_{i}+j l_{i}
$$

where $l_{i}$ is calculated using the following relation:

$$
l_{i}=\frac{b_{i}-a_{i}}{d_{i}+1} .
$$

Using Equations (6) and (7), the following relations are obtained:

$$
v_{1}^{i}=a_{i}+l_{i} \text { and } v_{d_{i}}^{i}=b_{i}-l_{i} \text {. }
$$

For the photovoltaic cell or panel, the following set of septets of parameters is considered:

$$
G=\left\{\left(v_{j_{1}}^{1}, v_{j_{2}}^{2}, v_{j_{3}}^{3}, v_{j_{4}}^{4}, v_{j_{5}}^{5}, v_{j_{6}}^{6}, v_{j_{7}}^{7}\right) \mid j_{i}=1, \cdots, d_{i}, i=1, \cdots, 7\right\} .
$$

$$
\begin{aligned}
& \text { PSDA calculates }\left(v_{k_{1}}^{1}, v_{k_{2}}^{2}, v_{k_{3}}^{3}, v_{k_{4}}^{4}, v_{k_{5}}^{5}, v_{k_{6}}^{6}, v_{k_{7}}^{7}\right) \text { so that } \\
& \operatorname{RMSE}\left(v_{k_{1}}^{1}, v_{k_{2}}^{2}, v_{k_{3}}^{3}, v_{k_{4}}^{4}, v_{k_{5}}^{5}, v_{k_{6}}^{6}, v_{k_{7}}^{7}\right)=\min _{g \in G} \operatorname{RMSE}(g) .
\end{aligned}
$$

The septet $\left(v_{k_{1}}^{1}, v_{k_{2}}^{2}, v_{k_{3}}^{3}, v_{k_{4}}^{4}, v_{k_{5}}^{5}, v_{k_{6}}^{6}, v_{k_{7}}^{7}\right)$ is an approximate solution of Equation (3). 


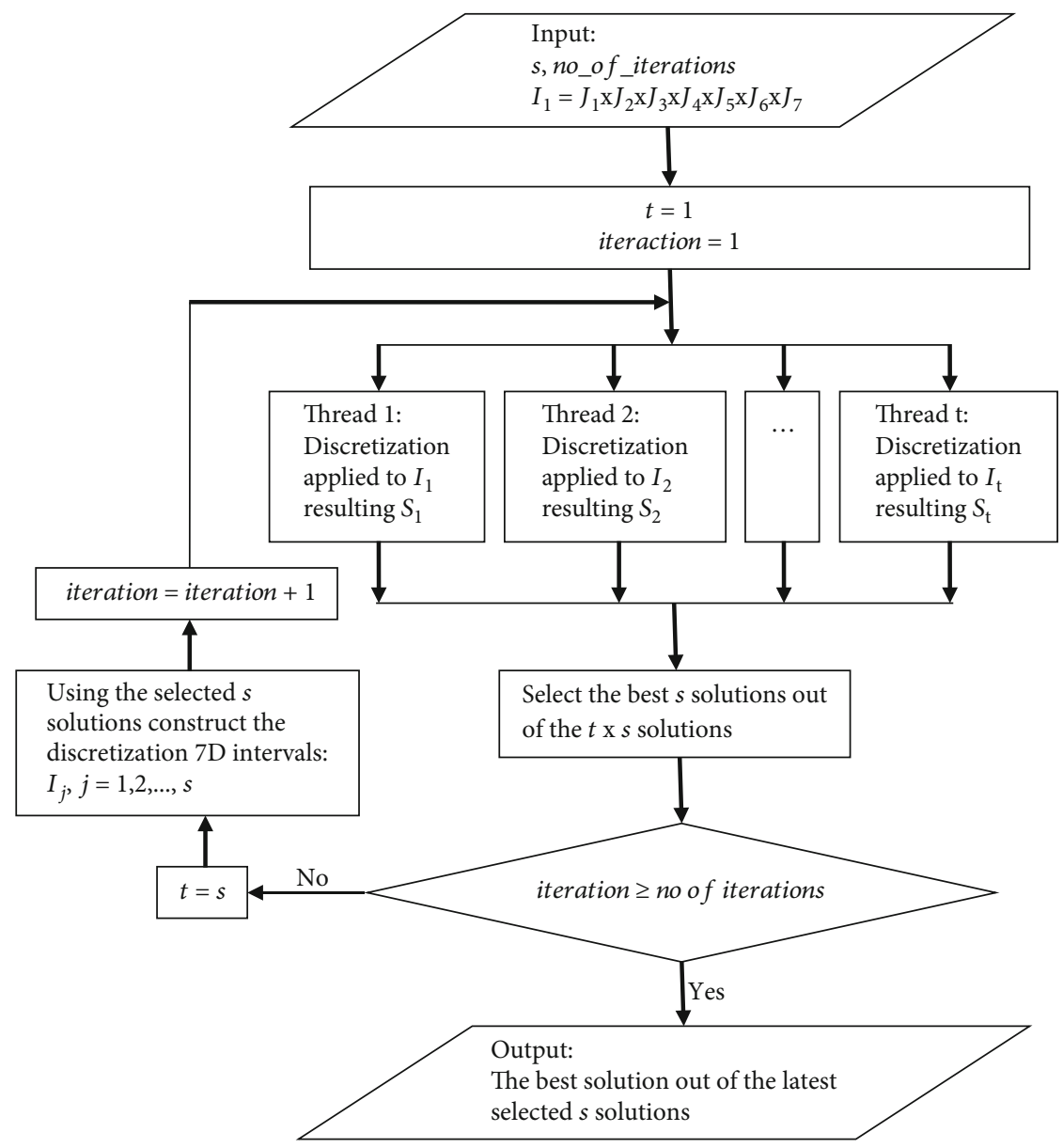

FIGURE 2: Flowchart of the parallel implementation of the algorithm.

TABLE 1: The seven parameters of the RTC photovoltaic cell.

\begin{tabular}{|c|c|c|c|c|c|c|c|c|}
\hline Algorithm & $\begin{array}{c}I_{\mathrm{ph}} \\
\mathrm{A}\end{array}$ & $\begin{array}{l}I_{\mathrm{od}} \\
\mu \mathrm{A}\end{array}$ & $\begin{array}{l}I_{\text {or }} \\
\mu \mathrm{A}\end{array}$ & $n_{\mathrm{d}}$ & $n_{\mathrm{r}}$ & $\begin{array}{l}R_{\mathrm{s}} \\
\Omega\end{array}$ & $\begin{array}{c}R_{\mathrm{sh}} \\
\Omega\end{array}$ & $\begin{array}{c}\text { RMSE } \\
\text { E-04 }\end{array}$ \\
\hline PSDA & 0.76077943 & 0.22615047 & 0.74934181 & 1.4510581 & 2.00119185 & 0.03674321 & 55.48427327 & 9.82473 \\
\hline PCE [4] & 0.760781 & 0.226015 & 0.749340 & 1.450923 & 2.000000 & 0.03674 & 55.483160 & 9.8248 \\
\hline STLBO [5] & 0.76078 & 0.22566 & 0.75217 & 1.45085 & 2.00000 & 0.03674 & 55.4920 & 9.8248 \\
\hline ISCE [7] & 0.76078108 & 0.22597409 & 0.74934898 & 1.4510167 & 2.000000 & 0.03674043 & 55.48544409 & 9.82484 \\
\hline Rcr-IJADE [8] & 0.76078108 & 0.22597414 & 0.74934851 & 1.45101670 & 2.000000 & 0.03674043 & 55.48543800 & 9.824849 \\
\hline EHA-NMS [10] & 0.76078108 & 0.22597420 & 0.74934836 & 1.45101674 & 2.000000 & 0.03674043 & 55.48544722 & 9.824849 \\
\hline NM-MPSO [10] & 0.76078 & 0.22476 & 0.75524 & 1.45054 & 1.99998 & 0.03675 & 55.5296 & 9.825 \\
\hline CSO [11] & 0.76078 & 0.22732 & 0.72785 & 1.45151 & 1.99769 & 0.036737 & 55.3813 & 9.8252 \\
\hline FPSO [19] & 0.76078 & 0.22731 & 0.72786 & 1.45160 & 1.99969 & 0.036737 & 55.3923 & 9.8253 \\
\hline $\mathrm{BMO}$ [12] & 0.76078 & 0.21110 & 0.87688 & 1.44533 & 1.99997 & 0.03682 & 55.8081 & 9.8262 \\
\hline CWOA [13] & 0.76077 & 0.24150 & 0.60000 & 1.45651 & 1.9899 & 0.03666 & 55.2016 & 9.8272 \\
\hline MABC [9] & 0.7607821 & 0.24102992 & 0.6306922 & 1.4568573 & 2.0000538 & 0.03671215 & 54.7550094 & 9.8276 \\
\hline GOTLBO [6] & 0.760752 & 0.220462 & 0.800195 & 1.448974 & 1.999973 & 0.036783 & 56.075304 & 9.83177 \\
\hline ABSO [12] & 0.76078 & 0.26713 & 0.38191 & 1.46512 & 1.981524 & 0.03657 & 54.6219 & 9.834 \\
\hline ICHS [14] & 0.76079 & 0.16791 & 0.97310 & 1.42814 & 1.92126 & 0.03690 & 56.8368 & 9.8635 \\
\hline GGHS [14] & 0.76056 & 0.37014 & 0.13504 & 1.49638 & 1.92998 & 0.03562 & 62.7899 & 10.684 \\
\hline SA [15] & 0.7623 & 0.4767 & 0.01 & 1.5172 & 2 & 0.0345 & 43.1034 & 166.4 \\
\hline
\end{tabular}




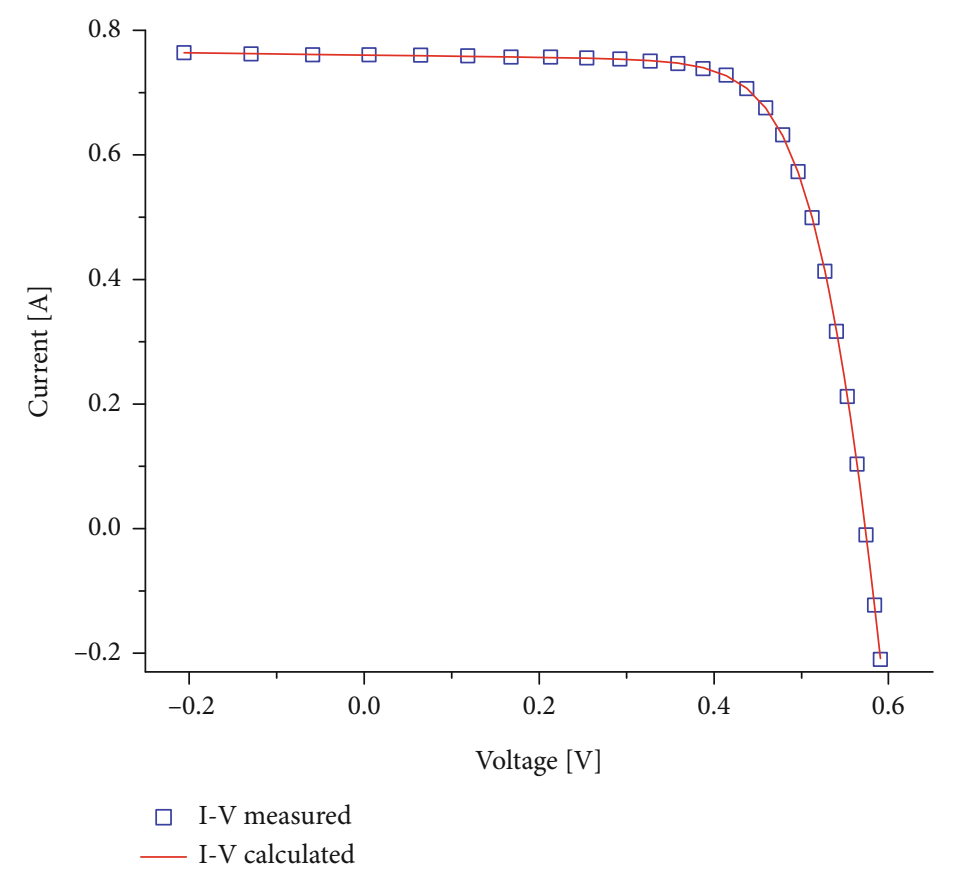

FIgURE 3: The I-V characteristics for RTC photovoltaic.

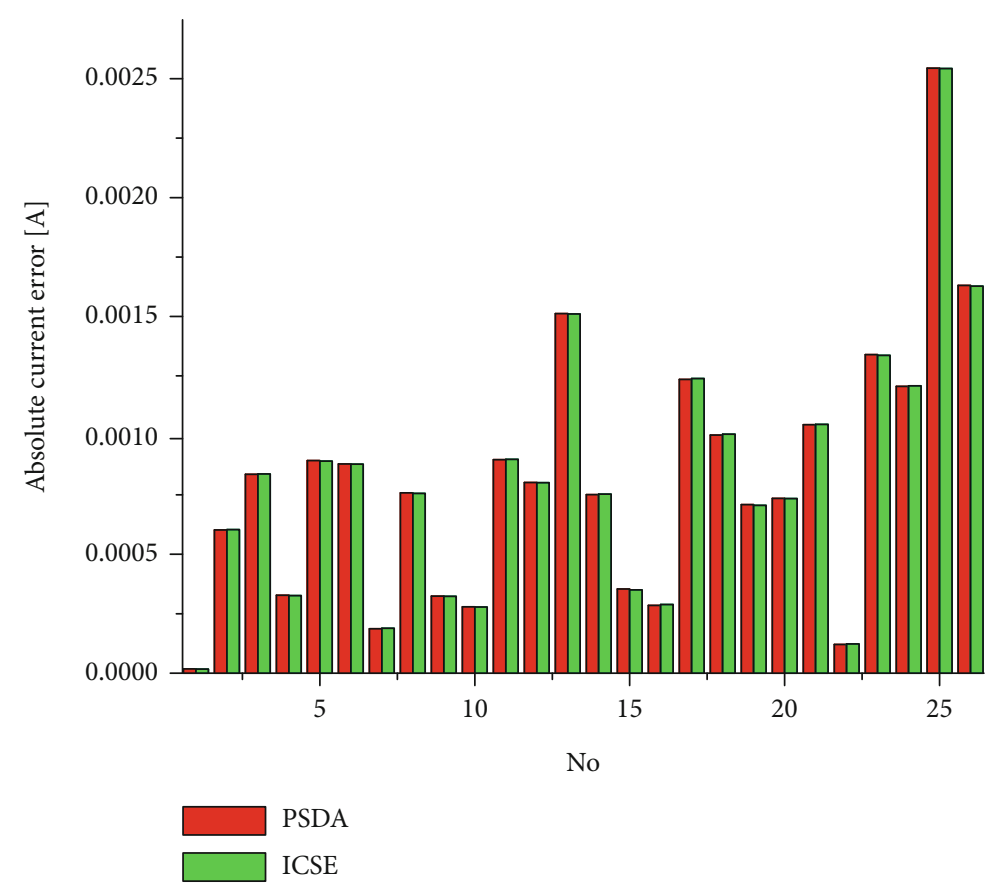

Figure 4: Absolute current error comparison for RTC.

2.2.2. Improving the Solution by Successive Discretization. The best approximate solution for Equation (3) can be improved using a successive discretization-refining initial solution.

The best $s \geq 1$ (" $s$ " is established at the beginning of the algorithm) septets are considered $g_{j}=\left(v_{k_{1}^{j}}^{1}, v_{k_{2}^{j}}^{2}, v_{k_{3}^{j}}^{3}, v_{k_{4}^{j}}^{4}\right.$ $\left., v_{k_{5}^{j}}^{5}, v_{k_{6}^{6}}^{6}, v_{k_{7}^{j}}^{7}\right)(j=1, \cdots, s)$ in the set $G$, having the smallest RMSE errors (Cotfas D.T., [3]). For each septet $g_{j}$, the solutions are refined for Equation (3) in the neighborhood of $g_{j}$ :

$$
J_{1}^{j} \times J_{2}^{j} \times J_{3}^{j} \times J_{4}^{j} \times J_{5}^{j} \times J_{6}^{j} \times J_{7}^{j},
$$

where

$$
J_{i}^{j}=\left[v_{k_{i}^{j}}^{i}-l_{i}, v_{k_{i}^{j}}^{i}+l_{i}\right], i=1, \cdots, 7 .
$$




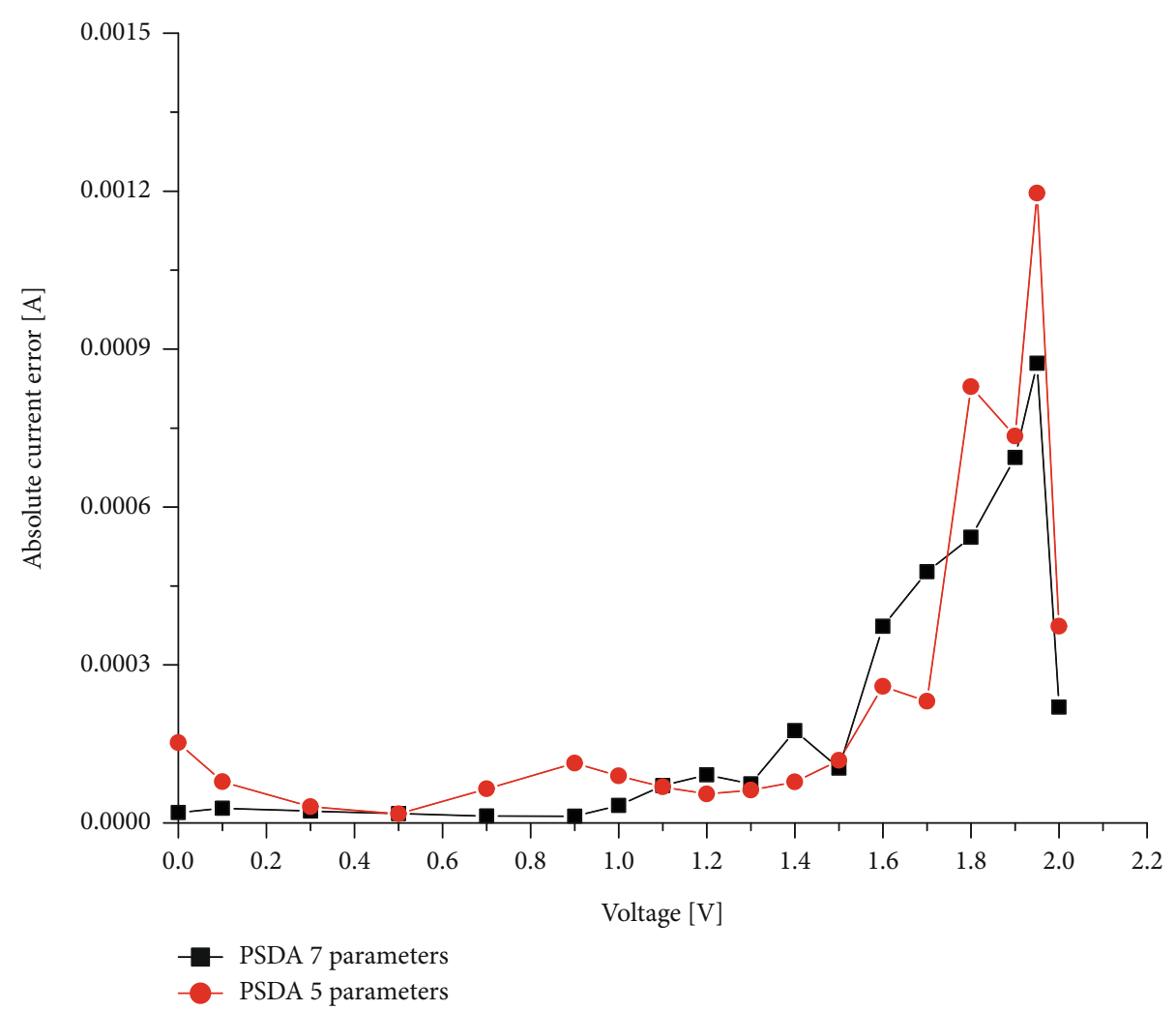

FIGURE 5: Comparison between the two-diode and one-diode model for RTC.

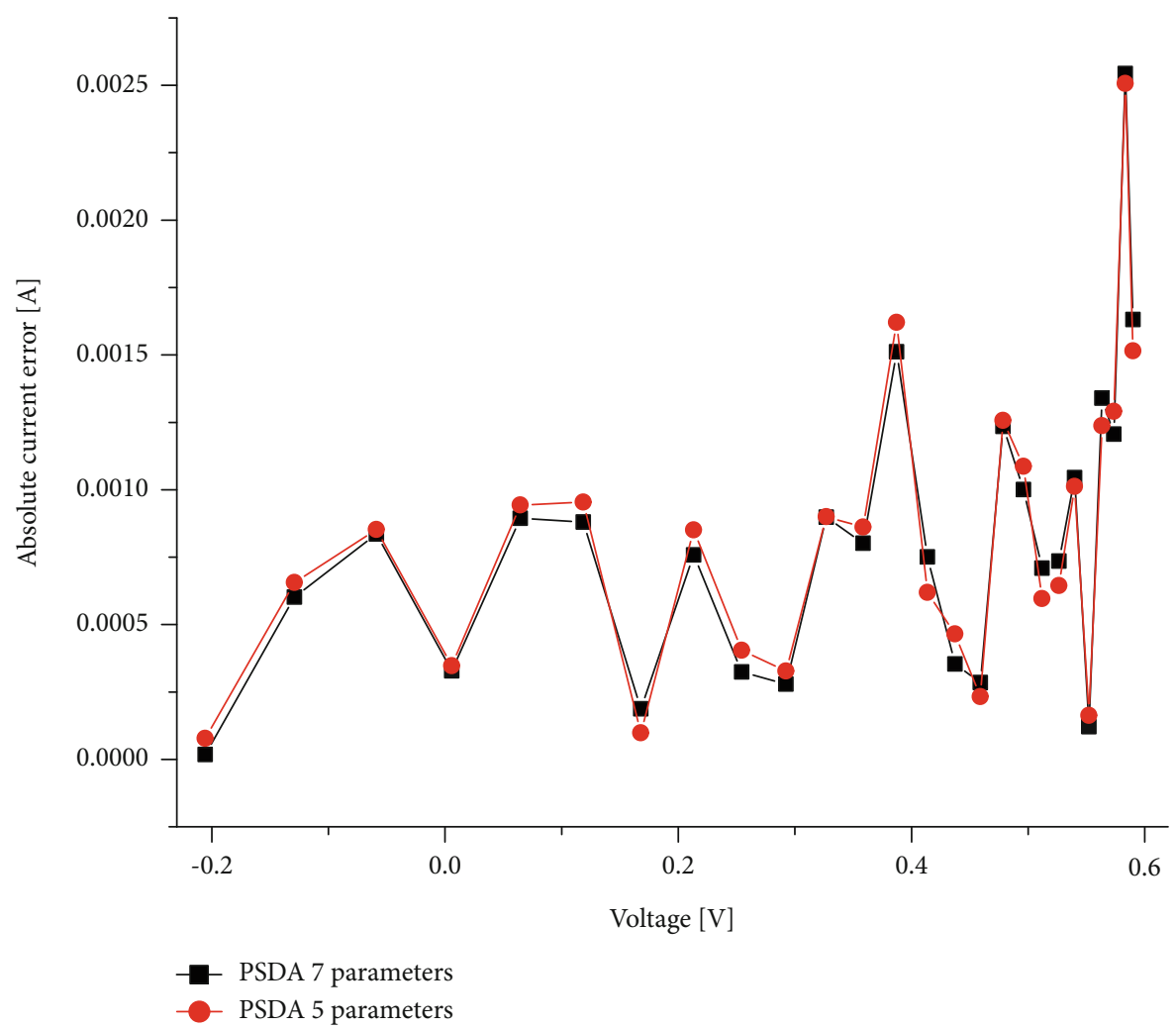

FIGURE 6: Comparison between the two-diode and one-diode model for STE 4/100 panel. 
TABLE 2: The seven parameters of the PWP201 photovoltaic panel.

\begin{tabular}{lcccccccc}
\hline Algorithm & $\begin{array}{c}I_{\mathrm{ph}} \\
\mathrm{A}\end{array}$ & $\begin{array}{c}I_{\mathrm{od}} \\
\mu \mathrm{A}\end{array}$ & $\begin{array}{c}I_{\mathrm{or}} \\
\mathrm{pA}\end{array}$ & $n_{\mathrm{d}}$ & $n_{\mathrm{r}}$ & $\begin{array}{c}R_{\mathrm{s}} \\
\Omega\end{array}$ & $\begin{array}{c}R_{\text {sh }} \\
\Omega\end{array}$ & $\begin{array}{c}\text { RMSE } \\
\mathrm{E}-03\end{array}$ \\
\hline PSDA & 1.032534389 & 2.511410784 & 1.14561846 & 1.317303011 & 1.31739967 & 1.234479859 & 721.503996 & 2.010645 \\
GCPSO [16] & 1.03238233 & 2.51291639 & 1.00005742 & 1.31730465 & 1.31693992 & 1.2392884 & 744.7153985 & 2.0465 \\
WDOWOAPSO [17] & 1.03238234 & 1.72494775 & 0.78796322 & 1.31730435 & 1.31730449 & 1.23928868 & 744.7142646 & 2.046535 \\
TVACPSO [17] & 1.031434 & 2.6381241 & 1 & 1.3209988 & 2.7777778 & 1.235632 & 821.65281 & 2.0530 \\
ABC-DE [18] & $1.0318 \mathrm{E}-01$ & 0.32774 & 2.4305 & 1.3443 & 1.3443 & 1.2062 & 845.2495 & 2.4000 \\
\hline
\end{tabular}

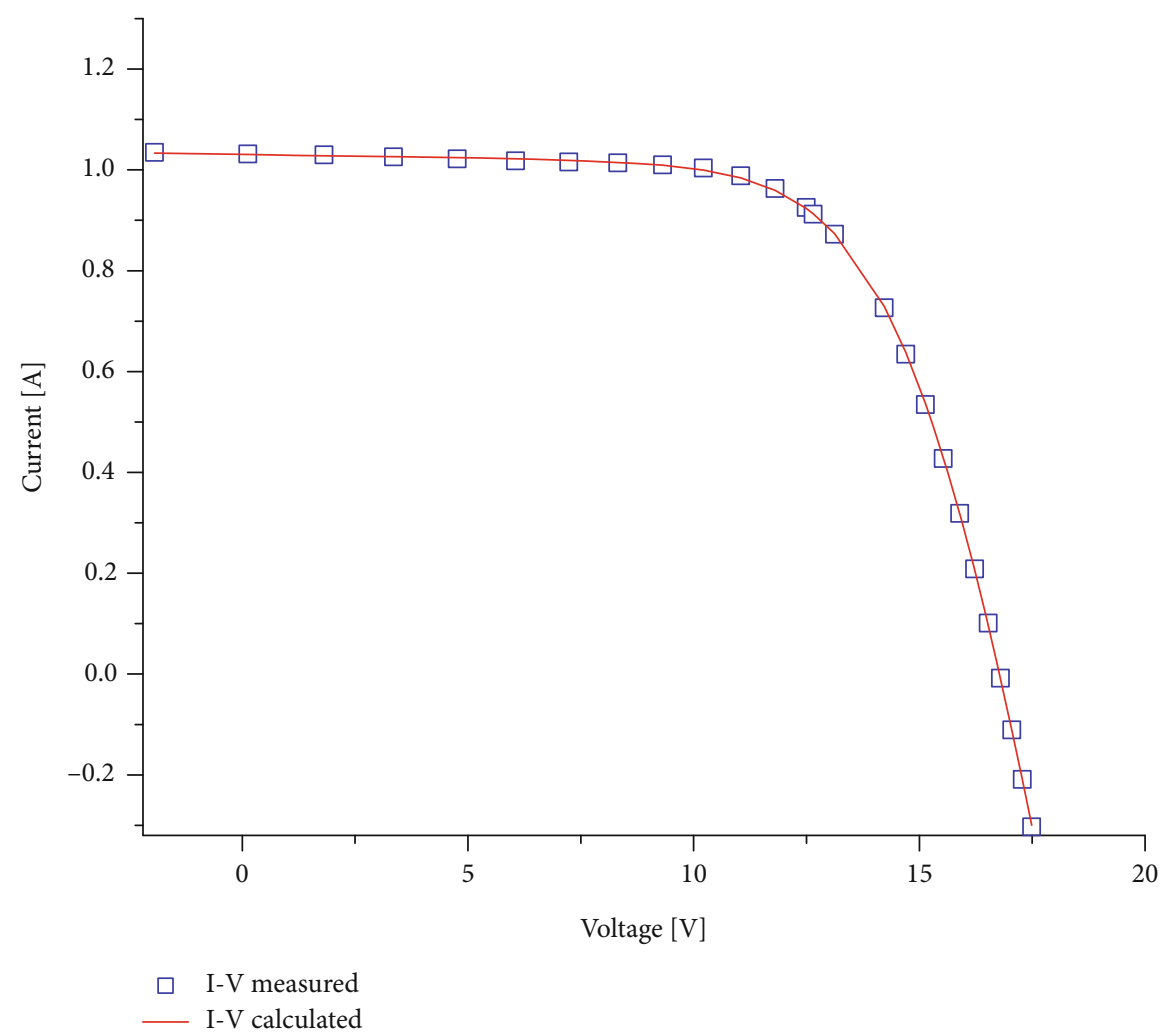

FIGURE 7: The I-V characteristics for PWP201 photovoltaic panel.

A total of $s$ septets are calculated for each interval from Equation $(11)(j=1, \cdots, s)$. From these $s^{2}$ values, the best $s$ solutions are selected, and the refining discretization is applied again. A predefined number of refining iterations are performed, and, in the end, the best overall septet is considered the final solution for Equation (3) (having the smallest RMSE error).

2.2.3. PSDA for Double-Diode Solar Cell Model. The idea of the algorithm is as follows. Discretizations are performed on given 7D intervals (see (11) and (12)). At the end of each iteration of the algorithm, "s" good solutions are constructed. In the vicinity of each of these solutions, a new discretization is applied to refine that solution. These discretizations can be performed in parallel on different machines or on different parallel threads on the same machine. The flowchart of the parallel implementation of the algorithm is presented in Figure 2.
Every discretization is executed $t$ times on parallel threads. In the first iteration, there is only one thread, but starting from the second iteration, there are $s$ parallel threads. Before starting the threads, all the values in the vector "finished" are set to the value false. Each discretization gets a $7 \mathrm{D}$ interval $I_{j}$, constructs $s$ solutions, and returns them in the set $S_{j}$. When the $j$-th discretization is finished, the $j$-th component of the vector "finished" is set to the value true. After all the values in the vector "finished" are true, it means that all the discretization threads are terminated, and all the sets $S_{j}(j=1, \cdots, t)$ are constructed.

On an 8-thread I7 processor by performing in parallel the discretization calls the algorithm finishes more than 6 times faster than the nonparallel implementation of the algorithm that computes the discretization on one thread. The above implementation of the algorithm proved to bring the processor utilization across all cores of the computer almost to the maximum (over 98\%). 


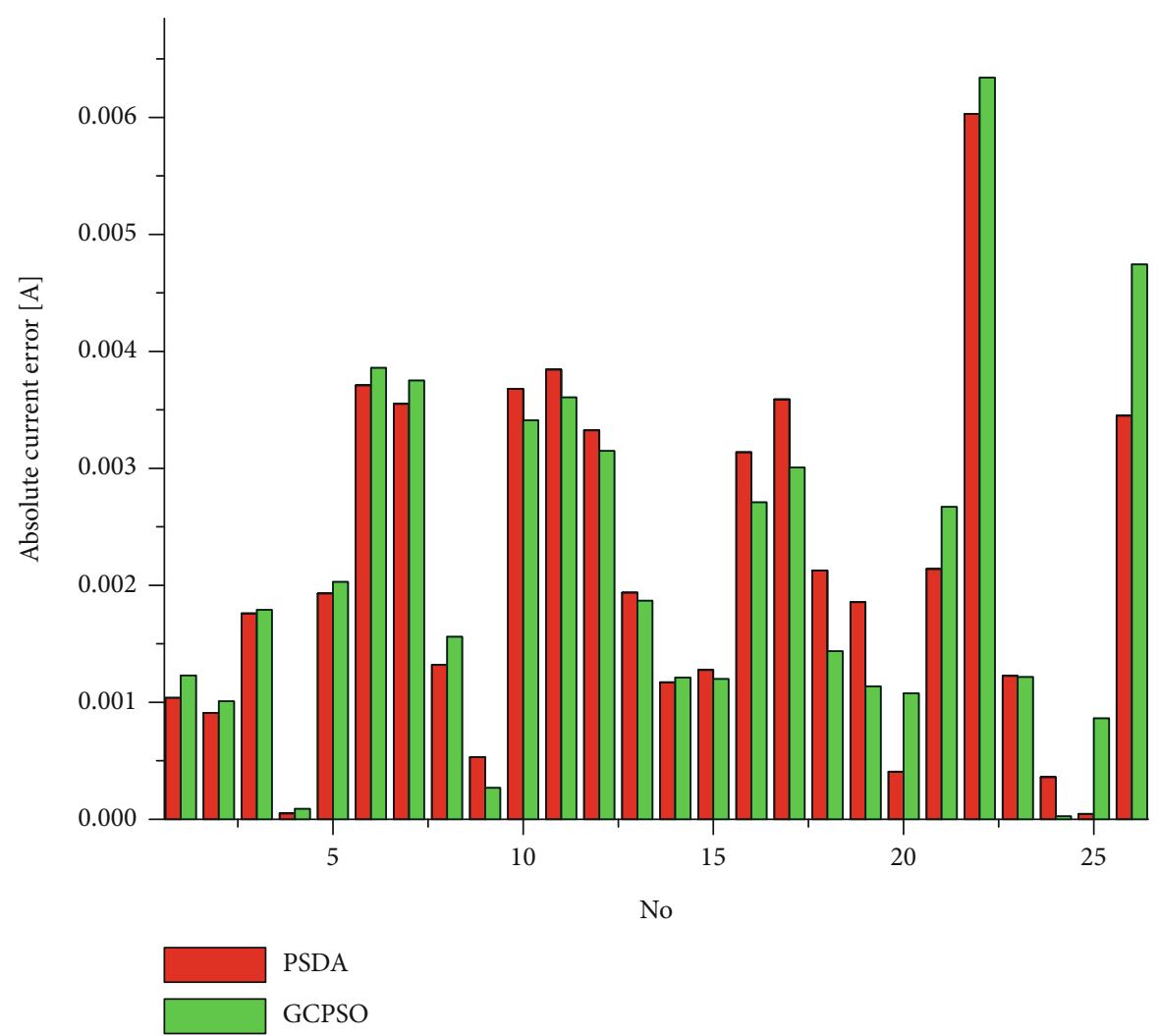

FIgURe 8: Absolute current error comparison for PWP201.

TABLE 3: The seven parameters of the Kyocera KC200GT photovoltaic panel.

\begin{tabular}{|c|c|c|c|c|c|c|c|c|}
\hline Algorithm & $\begin{array}{c}I_{\mathrm{ph}} \\
\mathrm{A}\end{array}$ & $\begin{array}{l}I_{\mathrm{od}} \\
\mu \mathrm{A}\end{array}$ & $\begin{array}{l}I_{\text {or }} \\
\mathrm{pA}\end{array}$ & $n_{\mathrm{d}}$ & $n_{\mathrm{r}}$ & $\begin{array}{l}R_{\mathrm{s}} \\
\Omega\end{array}$ & $\begin{array}{c}R_{\mathrm{sh}} \\
\Omega\end{array}$ & $\begin{array}{c}\text { RMSE } \\
\text { E-03 }\end{array}$ \\
\hline PSDA & 8.199056758 & $3.603852195 \mathrm{E}-4$ & $3.79468615 \mathrm{E}-5$ & 60.779659859 & 49.6103408 & 0.286457209 & 110.644764 & 11.98170 \\
\hline
\end{tabular}

\section{Results and Discussion}

The PSDA algorithm is applied for five datasets-one for RTC photovoltaic cell and the others for four photovoltaic panels: PWP201 [22], Kyocera KC200GT [23], Leibold Solar Module LSM 20 [24], and STE 4/100 [24]. The seven parameters for three out of these four panels are determined for the first time in this paper. The current voltage (I-V) characteristic for RTC is measured at $1000 \mathrm{~W} / \mathrm{m}^{2}$, and the temperature of the photovoltaic cell was $33^{\circ} \mathrm{C}$; PWP201 panel is measured at $1000 \mathrm{~W} / \mathrm{m}^{2}$, and the temperature of the photovoltaic panel was $45^{\circ} \mathrm{C}$; Kyocera KC200GT panel is measured at $1000 \mathrm{~W} / \mathrm{m}^{2}$ irradiance and $25^{\circ} \mathrm{C}$ temperature; for LSM 20 panel, the $\mathrm{I}-\mathrm{V}$ characteristic is measured at $360 \mathrm{~W} / \mathrm{m}^{2}$, and the temperature of the photovoltaic panel was $24^{\circ} \mathrm{C}$. The STE $4 / 100$ panel is measured at $900 \mathrm{~W} / \mathrm{m}^{2}$ irradiance and $22^{\circ} \mathrm{C}$ temperature. The limit intervals for the seven parameters of photovoltaic cell and panel are chosen to be similar with the ones used in the other algorithms [7] for the RTC photovoltaic cell and PWP201 panel. For the Kyocera KC200GT panel, Leibold Solar Module LSM 20, and STE $4 / 100$ panel, the two-diode model is applied for the first time.
3.1. RTC Photovoltaic Cell. The points of RTC photovoltaic cell and the current calculated using PSDA algorithm are shown in Table S1. The seven parameters of the RTC photovoltaic cell and the root mean square error determined by the PSDA algorithm and the values calculated by other algorithms are presented in Table 1 .

The I-V pairs of the RTC photovoltaic cell measured and calculated with PSDA algorithm are compared (see Figure 3). A very good matching can be observed, also proven by the lowest value of the root mean square error (see Table 1).

The absolute current error for RTC photovoltaic cell obtained with two algorithms, PSDA and ICSE, is presented in Figure 4. The PSDA absolute current error is lower than for ISCE ones for all measurement points without a uniform distribution. The highest values of the absolute error are around the open circuit voltage cell. The same distribution of the absolute current error is reported in [25].

In the absolute current error for RTC photovoltaic cell calculated with the two-diode model-the seven parameters and with the one-diode model-five parameters are presented in Figures 5 and 6 . It can be observed that the absolute current error calculated with the two-diode model is lower 


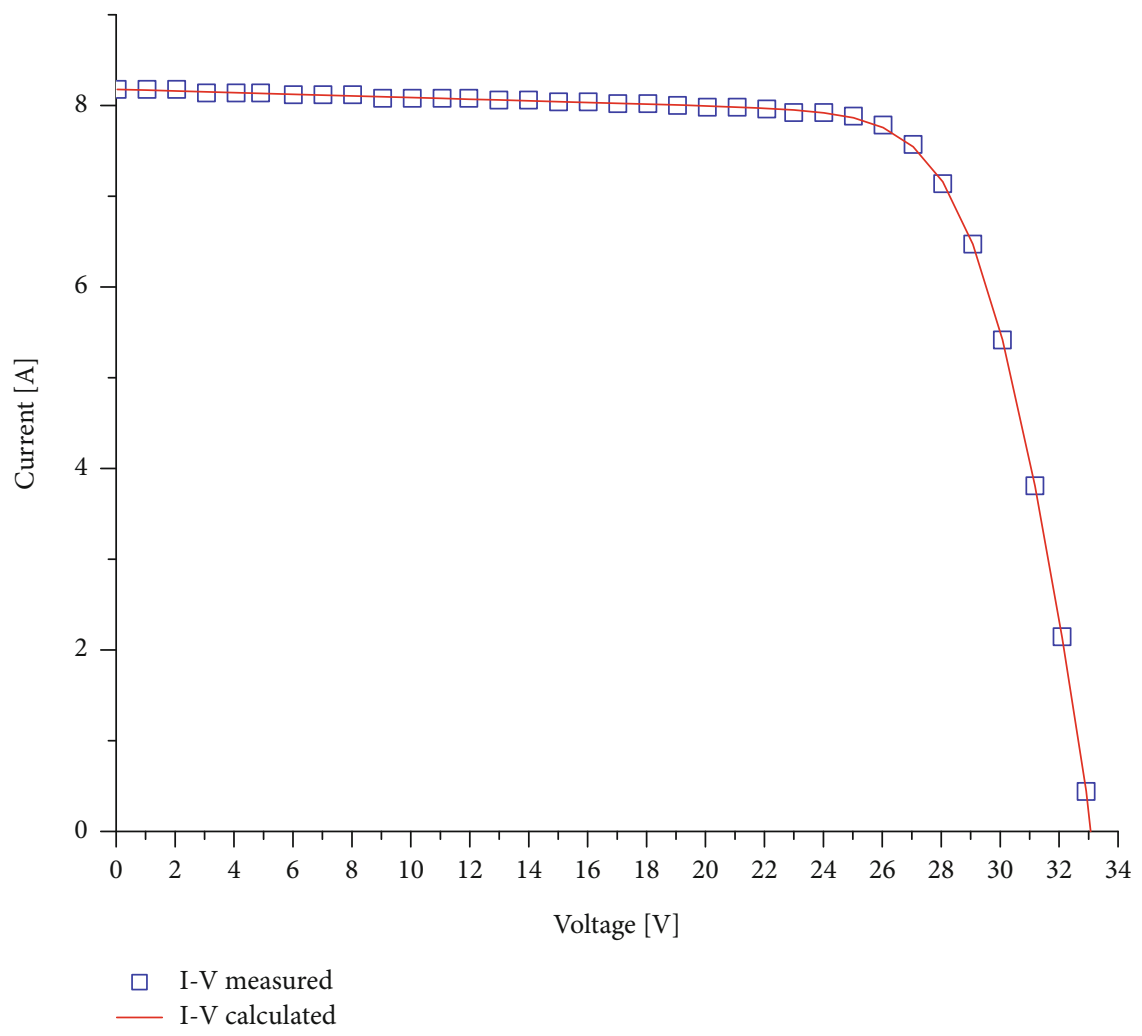

FIGURE 9: The I-V characteristics for Kyocera KC200GT photovoltaic panel.

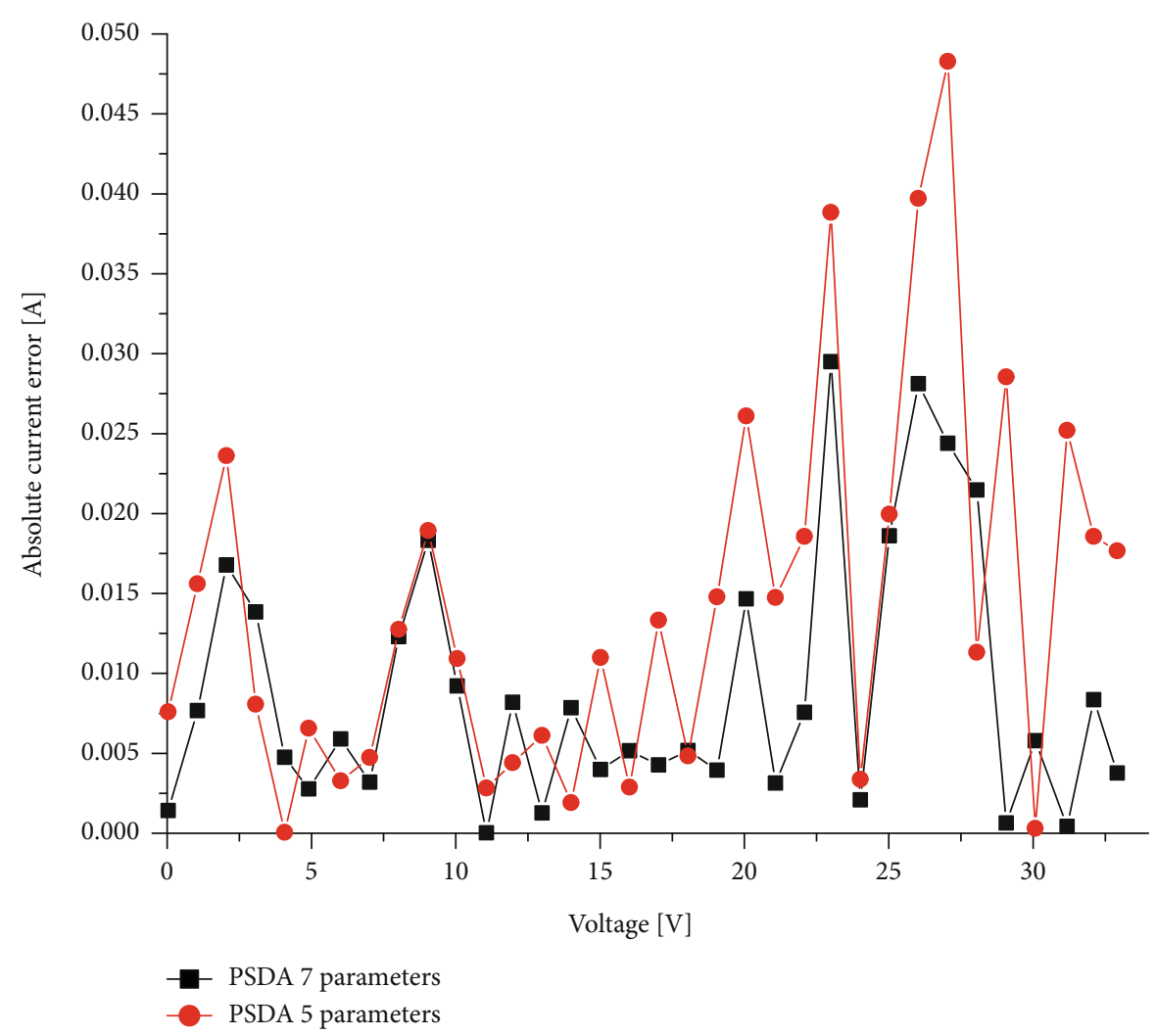

FIGURE 10: Comparison between the two-diodes and one-diode model for the Kyocera KC200GT panel. 
TABle 4: The seven parameters of the LSM 20 photovoltaic panel.

\begin{tabular}{|c|c|c|c|c|c|c|c|c|}
\hline Algorithm & $\begin{array}{c}I_{\mathrm{ph}} \\
\mathrm{A}\end{array}$ & $\begin{array}{l}I_{\mathrm{od}} \\
\mu \mathrm{A}\end{array}$ & $\begin{array}{l}I_{\text {or }} \\
\mu \mathrm{A}\end{array}$ & $n_{\mathrm{d}}$ & $n_{\mathrm{r}}$ & $\begin{array}{l}R_{\mathrm{s}} \\
\Omega\end{array}$ & $\begin{array}{c}R_{\mathrm{sh}} \\
\Omega\end{array}$ & $\begin{array}{c}\text { RMSE } \\
\text { E-04 }\end{array}$ \\
\hline PSDA & 0.153932108 & $2.988457072 \mathrm{E}-3$ & $3.17136807 \mathrm{E}-3$ & 26.632811966 & 26.75109623 & 6.1728707055 & 3546.219520 & 17.5889 \\
\hline
\end{tabular}

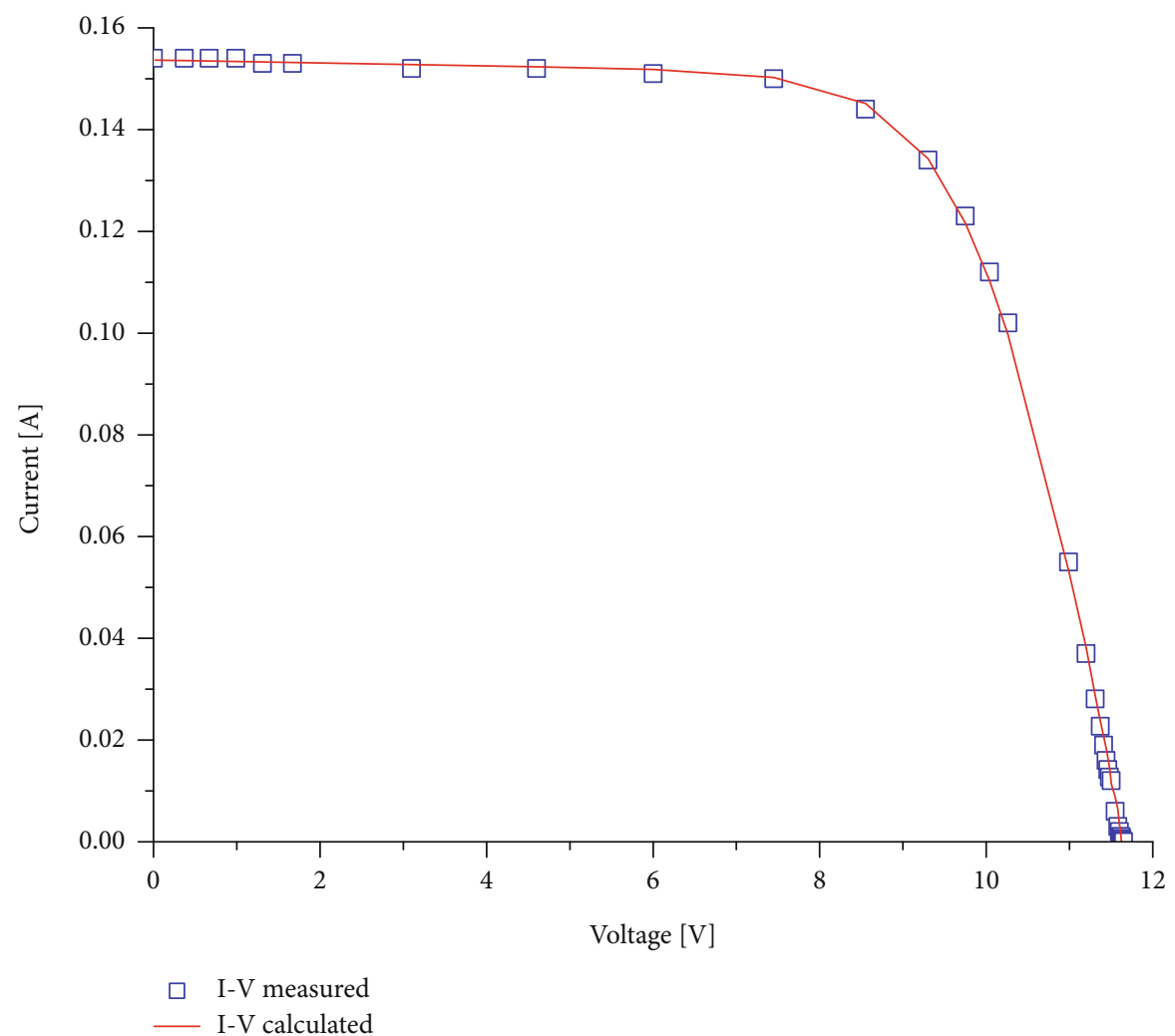

FIGURE 11: The I-V characteristics for LSM 20 photovoltaic panel.

than the ones determined with the one-diode model. This shows that the best solution for the photovoltaic cell parameters is obtained using the two-diode model.

3.2. PWP201 Photovoltaic Panel. The points of PWP201 photovoltaic panel and the current calculated using PSDA algorithm are shown in Table S2. The seven parameters of the PWP201 photovoltaic panel and the root mean square error determined through the PSDA algorithm and the values calculated through other algorithms are presented in Table 2.

The seven parameters of the PWP201 photovoltaic panel, the root mean square error determined through the PSDA algorithm, and the values calculated through other four algorithms are presented in Table 2. PSDA gives similar solutions to other algorithms but with the lowest root mean square error.

By comparing the five algorithms taken into account for PWP201 photovoltaic panel, it can be observed that all seven parameters fluctuate in the function of the applied algorithm. These fluctuations are higher than the ones for RTC photovoltaic cell. The number of I-V pairs is the same for the two photovoltaic devices, but the voltage interval is much higher for the panel than for the photovoltaic cell, and the calculations are made for fewer points. The I-V characteristics of the PWP201 photovoltaic panel measured and calculated with PSDA algorithm are compared (see Figure 7), and the matching is very good.

The absolute current error for PWP201 photovoltaic panel calculated with two algorithms, PSDA and GCPSO, is presented in Figure 8. The PSDA absolute current error is lower than for GCPSO ones for the majority of the measurements.

The seven parameters for the next three panels are determined for the first time using PSDA. In the literature, there are no other values for the two-diode model to compare with, and so, the solutions are compared with the best ones obtained for the one-diode model.

3.3. Kyocera KC200GT Photovoltaic Panel. The points of Kyocera KC200GT photovoltaic panel and the current calculated using PSDA algorithm are shown in Table S3. The seven parameters of the Kyocera KC200GT photovoltaic panel and the root mean square error determined through the PSDA algorithm are presented in Table 3. 


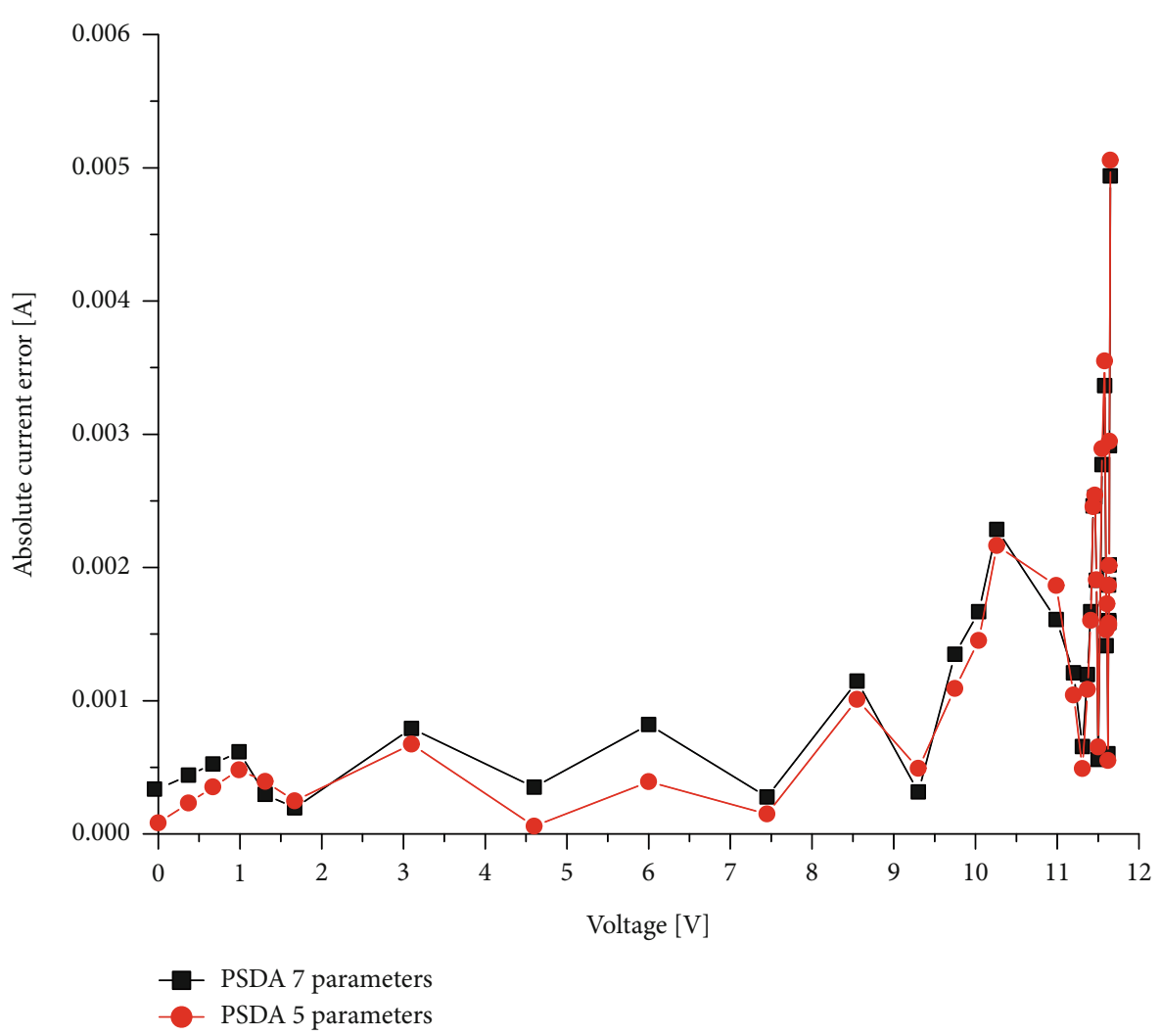

Figure 12: Comparison between the two-diode and one-diode model for LSM 20 panel.

TABLE 5: The seven parameters of the STE 4/100 photovoltaic panel.

\begin{tabular}{|c|c|c|c|c|c|c|c|c|}
\hline Algorithm & $\begin{array}{c}I_{\mathrm{ph}} \\
\mathrm{A}\end{array}$ & $\begin{array}{l}I_{\mathrm{od}} \\
\mu \mathrm{A}\end{array}$ & $\begin{array}{l}I_{\text {or }} \\
\mu \mathrm{A}\end{array}$ & $n_{\mathrm{d}}$ & $n_{\mathrm{r}}$ & $\begin{array}{l}R_{\mathrm{s}} \\
\Omega\end{array}$ & $\begin{array}{c}R_{\mathrm{sh}} \\
\Omega\end{array}$ & $\begin{array}{c}\text { RMSE } \\
\text { E-04 }\end{array}$ \\
\hline PSDA & 0.026434533 & $7.468752134 \mathrm{E}-5$ & $4.91018373 \mathrm{E}-3$ & 4.2799344307 & 5.199781435 & 1.1820913872 & 2109.248002 & 3.348041 \\
\hline
\end{tabular}

The calculated I-V characteristic of the Kyocera KC200GT photovoltaic panel using PSDA algorithm, which consists 54 multicrystalline silicon photovoltaic cells connected in series, is matching with the I-V points measured [23] (Figure 9).

The comparison between the absolute errors of the current for the one and two-diode models shows that the last model gives for the majority of the I-V points better results (Figure 10). The two-diode model has to be used when the accuracy in calculation of the photovoltaic panel parameters is crucial.

3.4. Leibold Solar Module LSM 20. The points of LSM 20 photovoltaic panel and the current calculated using PSDA algorithm are shown in Table S4. The seven parameters of the LSM 20 photovoltaic panel RMSE determined through the PSDA algorithm are presented in Table 4.

The I-V characteristics of the Leibold Solar Module LSM 20 measured and calculated with PSDA algorithm are compared (see Figure 8). The matching for the measured and calculated points is very good; this is confirmed by the root mean square error which is very small (Table 4) (Figure 11).
Figure 12 illustrates the absolute error for the current, obtained for the LSM 20 photovoltaic panel, using the oneand two-diode models. The RMSE obtained with the twodiode model is smaller than the one obtained with the onediode model, which is $17.64 \mathrm{E}-4$. This is confirmed by the absolute error obtained through both models. The higher values of the absolute error are splited for the two models used.

3.5. Leybold Solar Module STE 4/100. The points of STE 4/100 photovoltaic panel and the current calculated using PSDA algorithm are shown in Table S5. The seven parameters of the STE 4/100 photovoltaic panel and the root mean square error determined through the PSDA algorithm are presented in Table 5.

The I-V pairs of the Leybold Solar Module STE 4/100 measured and calculated with PSDA algorithm are compared (see Figure 13). A very good matching can be observed, also proven by the lowest value of the root mean square error (see Table 5).

The absolute current error for STE 4/100 photovoltaic panel calculated with the two-diode model and with the 


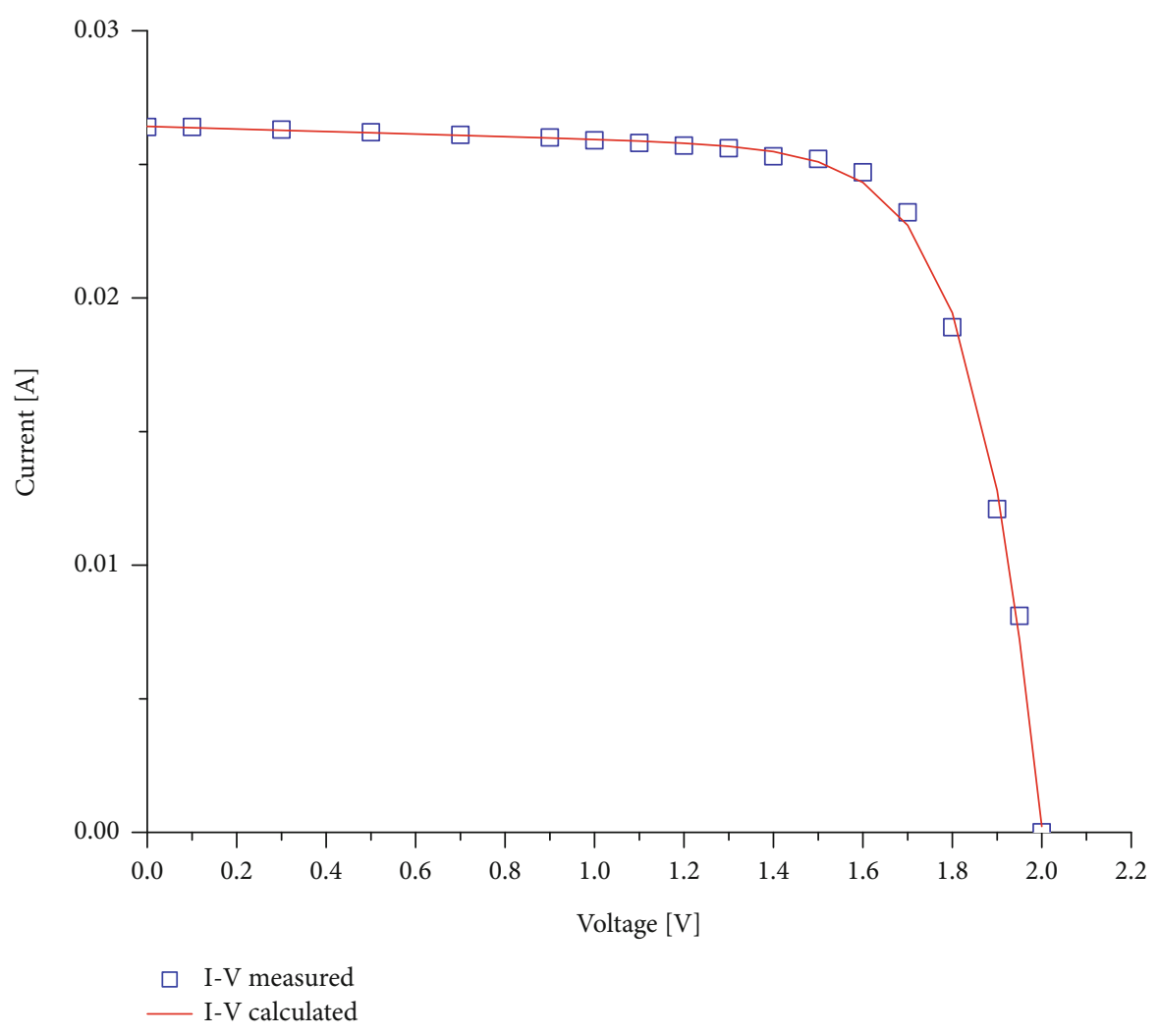

FIgURE 13: The I-V characteristics for STE 4/100 photovoltaic panel.

one-diode model is presented in Figure 5. It can be observed that the absolute current error calculated for the majority points with the two-diode model is lower than the ones determined with the one-diode model. The RMSE obtained with the one-diode model is $4.0853 \mathrm{E}-4$ (Figure 6).

PSDA algorithm was executed with $s=10$ and with a total of 4 iterations on an 8-thread I7 processor at $1.9 \mathrm{GHz}$. It ended in 46 seconds. The nonparallel implementation took almost 5 minutes to finish (more than 6 times slower).

\section{Conclusions}

The estimation of the parameters for the solar cells and panels is very important for designing, simulation, and evaluation of the performance of photovoltaic systems. This problem is currently intensively studied by many researchers. In this paper, the Parallelized Successive Discretization Algorithm is developed and presented to deal with this problem. It is a metaheuristic approach that proved to be a powerful tool for approximating the solution of the implicit transcendental equation problem of finding the seven parameters for the two-diode model. The problem is transformed into a multidimensional optimization problem of minimizing the root mean square error and then solved using multiple and increasing in refining discretizations. The parallel implementation helped to speed up the algorithm since the amount of computations is high and complex. PSDA proves to be fast and reliable that gives very good (the best) estimation of parameters among the current known algorithms used for the two-diode model. In this paper, the results given by PSDA for one photovoltaic cell and for four panels were given for the two-diode model. The parameters were obtained for the first time for three panels for which only the parameters of one-diode model were determined in the literature.

The sensitivity analysis of the PSDA algorithm is one of the future research directions, and another is to use the PSDA algorithm to extract the parameters of the other photovoltaic cells and panels, for example organic photovoltaic cell using a proper equivalent circuit and the corresponding mathematical model.

\section{Data Availability}

Data in supplementary information files.

\section{Conflicts of Interest}

The authors declare that there is no conflict of interest regarding the publication of this paper.

\section{Acknowledgments}

This publication was funded by the University Transilvania of Brasov. 


\section{Supplementary Materials}

Table S1: the current calculated using the PSDA algorithm and the relative error, calculated by subtracting the calculated from the measured current values for RTC photovoltaic cell. Table S2: the current calculated using the PSDA algorithm and the relative error for PWP201 photovoltaic panel. Table S3: the current calculated using the PSDA algorithm and the relative error for LSM 20 photovoltaic panel. Table S4: the current calculated using the PSDA algorithm and the relative error for LSM 20 photovoltaic panel. Table S5: the current calculated using the PSDA algorithm and the relative error for LSM 20 photovoltaic panel. (Supplementary Materials)

\section{References}

[1] D. T. Cotfas, P. A. Cotfas, and S. Kaplanis, "Methods to determine the dc parameters of solar cells: a critical review," Renewable and Sustainable Energy Reviews, vol. 28, pp. 588-596, 2013.

[2] D. T. Cotfas, P. A. Cotfas, and S. Kaplanis, "Methods and techniques to determine the dynamic parameters of solar cells: review," Renewable and Sustainable Energy Reviews, vol. 61, pp. 213-221, 2016.

[3] D. T. Cotfas, A. M. Deaconu, and P. A. Cotfas, "Application of successive discretization algorithm for determining photovoltaic cells parameters," Energy Conversion and Management, vol. 196, pp. 545-556, 2019.

[4] Y. Zhang, P. Lin, Z. Chen, and S. Cheng, "A population classification evolution algorithm for the parameter extraction of solar cell models," International Journal of Photoenergy, vol. 2016, Article ID 2174573, 16 pages, 2016.

[5] Q. Niu, H. Zhang, and K. Li, “An improved TLBO with elite strategy for parameters identification of PEM fuel cell and solar cell models," International Journal of Hydrogen Energy, vol. 39, no. 8, pp. 3837-3854, 2014.

[6] X. Chen, K. Yu, W. Du, W. Zhao, and G. Liu, "Parameters identification of solar cell models using generalized oppositional teaching learning based optimization," Energy, vol. 99, pp. 170-180, 2016.

[7] X. Gao, Y. Cui, J. Hu et al., "Parameter extraction of solar cell models using improved shuffled complex evolution algorithm," Energy Conversion and Management, vol. 157, pp. 460-479, 2018.

[8] W. Gong and Z. Cai, "Parameter extraction of solar cell models using repaired adaptive differential evolution," Solar Energy, vol. 94, pp. 209-220, 2013.

[9] M. Jamadi, F. Merrikh-Bayat, and M. Bigdeli, "Very accurate parameter estimation of single- and double-diode solar cell models using a modified artificial bee colony algorithm," International Journal of Energy and Environmental Engineering, vol. 7, no. 1, pp. 13-25, 2016.

[10] Z. Chen, L. Wu, P. Lin, Y. Wu, and S. Cheng, "Parameters identification of photovoltaic models using hybrid adaptive Nelder-Mead simplex algorithm based on eagle strategy," Applied Energy, vol. 182, pp. 47-57, 2016.

[11] L. Guo, Z. Meng, Y. Sun, and L. Wang, "Parameter identification and sensitivity analysis of solar cell models with cat swarm optimization algorithm," Energy Conversion and Management, vol. 108, pp. 520-528, 2016.

[12] A. Askarzadeh and A. Rezazadeh, "Extraction of maximum power point in solar cells using bird mating optimizer-based parameters identification approach," Solar Energy, vol. 90, pp. 123-133, 2013.

[13] D. Oliva, M. Abd El Aziz, and A. Ella Hassanien, "Parameter estimation of photovoltaic cells using an improved chaotic whale optimization algorithm," Applied Energy, vol. 200, pp. 141-154, 2017.

[14] A. Askarzadeh and A. Rezazadeh, "Parameter identification for solar cell models using harmony search-based algorithms," Solar Energy, vol. 86, no. 11, pp. 3241-3249, 2012.

[15] K. M. El-Naggar, M. R. AlRashidi, M. F. AlHajri, and A. K. AlOthman, "Simulated annealing algorithm for photovoltaic parameters identification," Solar Energy, vol. 86, no. 1, pp. 266-274, 2012.

[16] H. G. G. Nunes, J. A. N. Pombo, S. J. P. S. Mariano, M. R. A. Calado, and J. A. M. Felippe de Souza, "A new high performance method for determining the parameters of PV cells and modules based on guaranteed convergence particle swarm optimization," Applied Energy, vol. 211, pp. 774-791, 2018.

[17] H. G. G. Nunes, J. A. N. Pombo, P. M. R. Bento, S. J. P. S. Mariano, and M. R. A. Calado, "Collaborative swarm intelligence to estimate PV parameters," Energy Conversion and Management, vol. 185, pp. 866-890, 2019.

[18] O. Hachana, K. E. Hemsas, G. M. Tina, and C. Ventura, "Comparison of different metaheuristic algorithms for parameter identification of photovoltaic cell/module," Journal of Renewable and Sustainable Energy, vol. 5, no. 5, article 053122, 2013.

[19] S. M. Ebrahimi, E. Salahshour, M. Malekzadeh, and F. Gordillo, "Parameters identification of PV solar cells and modules using flexible particle swarm optimization algorithm," Energy, vol. 179, pp. 358-372, 2019.

[20] S. Kotsiantis and D. Kanellopoulos, "Discretization techniques: a recent survey," GESTS International Transactions on Computer Science and Engineering, vol. 32, pp. 47-58, 2006.

[21] S. Garcia, J. Luengo, J. A. Saez, V. Lopez, and F. Herrera, “A survey of discretization techniques: taxonomy and empirical analysis in supervised learning," IEEE Transactions on Knowledge and Data Engineering, vol. 25, no. 4, pp. 734-750, 2013.

[22] T. Easwarakhanthan, J. Bottin, I. Bouhouch, and C. Boutrit, "Nonlinear minimization algorithm for determining the solar cell parameters with microcomputers," International Journal of Solar Energy, vol. 4, no. 1, pp. 1-12, 1986.

[23] J. Ma, Optimization approaches for parameter estimation and maximum power point tracking (MPPT) of photovoltaic systems, [Ph.D. thesis], University of Liverpool Repository, Liverpool, 2014.

[24] F. F. Muhammad, A. W. Karim Sangawi, S. Hashim, S. K. Ghoshal, I. K. Abdullah, and S. S. Hameed, "Simple and efficient estimation of photovoltaic cells and modules parameters using approximation and correction technique," PLoS One, vol. 14, no. 5, article e0216201, 2019.

[25] H. Chen, S. Jiao, M. Wang, A. A. Heidari, and X. Zhao, "Parameters identification of photovoltaic cells and modules using diversification-enriched Harris hawks optimization with chaotic drifts," Journal of Cleaner Production, vol. 244, article 118778, 2020. 